\title{
A Method of Making a Topographic Map
}

\section{F. V. Emerson}

To cite this article: F. V. Emerson (1906) A Method of Making a Topographic Map, Journal of Geography, 5:10, 461-467, DOI: 10.1080/00221340608986158

To link to this article: http://dx.doi.org/10.1080/00221340608986158

\section{Published online: 20 May 2008.}

Submit your article to this journal

Џll Article views: 4

Q View related articles $\sqsubset$ 


\section{A METHOD OF MAKING A TOPOGRAPHIC MAP}

BY F. V. EMERSON

Columbia, Mo.

1 MAP is a kind of written language by which an immense amount A of information may be conveyed in a brief space and, like any 1 other language, maps must be thoroughly understood before their facts can be well appreciated. Owing to our training which begins in

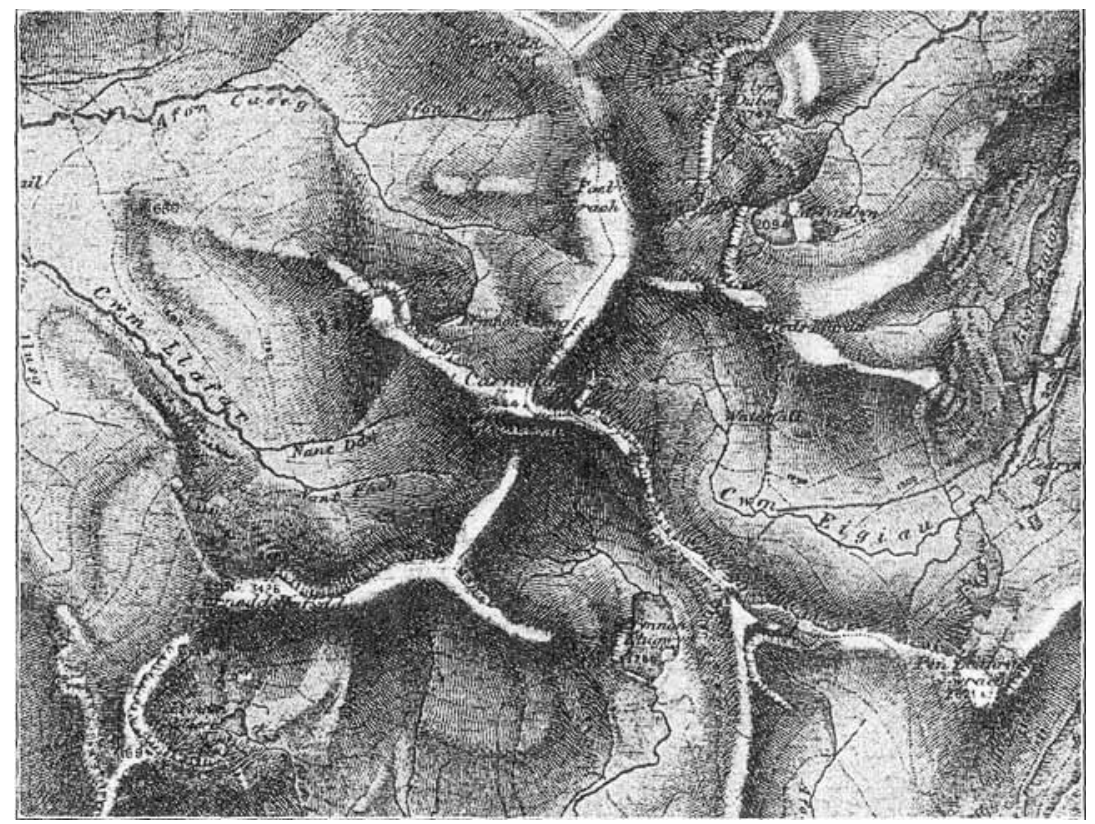

Fig. I

Topography from County Caernarvon in North Western Wales; Bangor sheet No. ro6, ordinance survey of England and Wales. Scale $I$ inch $=1$ mile. Both hachures and contours are used, the contour interval being 250 feet.

the lower school grades, most of us read the ordinary location maps with ease. We get a more or less accurate idea of the two principal things that they show, namely, distance and direction.

For a complete picture of a region, the third dimension must be shown. One must know the hills and valleys, the highlands and lowlands and their various forms and dimensions, or, in another word, the relief of a region. The maps that show relief are of two general classes, hachure maps and 
contour maps. The maps of most European countries are of the first class, Fig. I. They are easy to read and give a vivid impression of the surface. They are really generalized drawings. The disadvantage of the hachure map is that it is of necessity inaccurate. Even the most careful shading will fail to bring out the details of elevation that can be shown on zontour maps, and, when the relief is of great variety, the shading obscures the place names and makes close reading somewhat difficult. But, for the general reader, the hachure map gives a general view of relief without much mental effort.

The maps of the United States Geological Survey, in which it is proposed eventually to present the entire United States, are of the contour variety. Relief is represented by lines that are drawn through places having the same altitude. The function of a contour line may be illustrated by supposing the sea to rise to an altitude of say six hundred feet. Then the six hundred-foot line would be coincident with the shore line. The advantage of this method is the possibility of extreme accuracy. By careful work, the exact altitude of any place can be shown. In general, the contours do not obscure the printing and other features of the map. It should be said that owing to the large areas covered, the average topographic map of the Survey is not so accurate as it seems to be. The great disadvantage of this map is the difficulty that the average person has in reading it. Its symbols are purely conventional and do not appeal to the eye as do the hachure maps. It takes considerable time to learn the alphabet of these maps, and generally a longer time so to master them that one does not need to spell out their meaning.

The ability to interpret contour maps may be gained by studying the maps themselves, by comparing the maps with the surface mapped, or by mapping a given surface. All these methods are useful, but the last is perhaps least used. The writer's experience in summer school work goes to show that time spent in actual mapping of some surface is profitable and is one of the quickest and most satisfactory methods of learning the sontour map language.

While it is true that rapid, accurate contour mapping requires trained men, almost anyone can by care make an accurate contour map. The method to be explained may perhaps be best presented by glancing at the methods of a professional topographer. All field mapping is done on a "plane table." This is simply a flat top set on tripod so that it can be turned in any direction. In one side of the table a compass needle is sunk, so that the table may be set in a north south direction. The paper on which the 
map is to be drawn is fastened to the table. The north part of the map can then be placed at the top of the sheet according to the usual convention.

A base line is measured, say 100 feet long. The measuring is done as carefully as possible, because a good many determinations will be taken from this line without direct measurement. The base line is represented

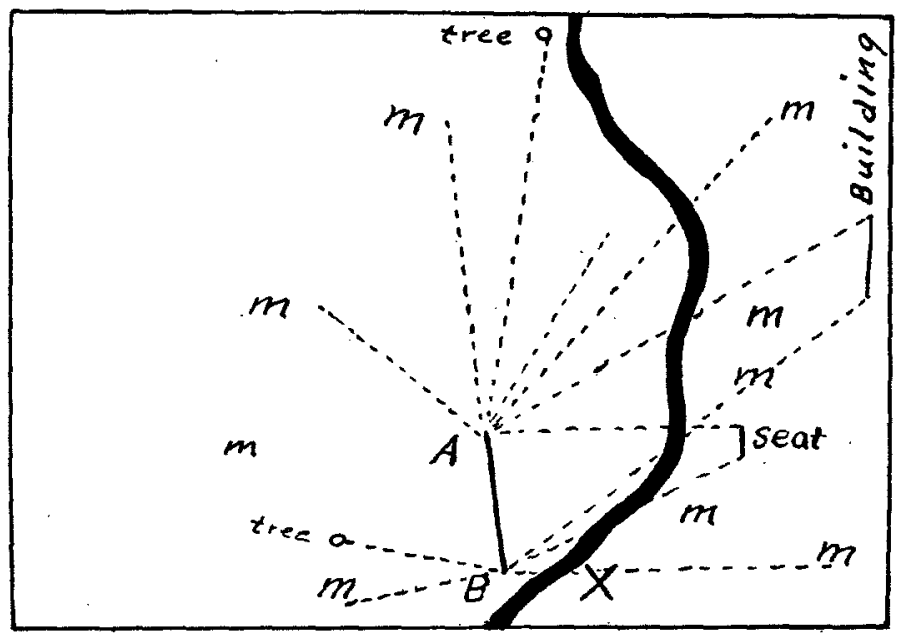

Fis. 2

Sketch showing locations. The building and seat in the eastern half of the map were located by intersection; the other points were located by traverses.

on the map by a line say io centimeters long. At each end of the base line observations are taken on various objects, and their angles with the base line are found. These angles are then plotted on the map and the relative positions of the various objects are determined. For example, if A, B, Fig. 2, represents the base line, by plotting angles at $A$ and $B$ and continuing their sides until they intersect, the position of the rustic seat can be determined. This is the method of intersection. By continuing the process a large number of places can be located often from one base line.

If for any reason the intersection method is not used, the traverse method can be employed. Suppose the point $M$ is to be determined. Its direction from $A$ or $B$ is found and its distance is measured. It is then plotted on the map according to the scale in use.

The contours are drawn somewhat as follows: Suppose a point $X$ is on a hill top. The topographer finds the altitude by the aneroid barometer.or by measurement from a point whose altitude is known. He has 
also determined the altitude of variou's other points. But he does most of the work by sketching in the contours. This sketching requires skill and a knack for the work. The accuracy of the sketching of course varies with the topographer. The above description is not an exact account, but

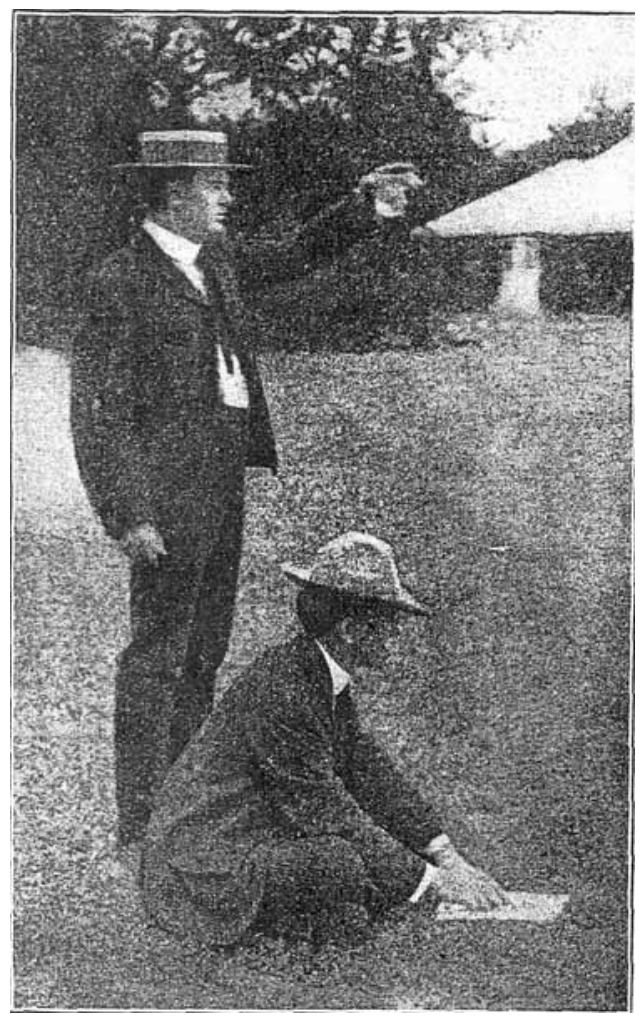

FIs. 3

The standing figure shows the method of taking levels; the other figure shows the method of getting the direction upon the map of different points.

it includes the fundamental operations and may make clearer the special method to be described.

The method used for class work is a rough imitation of that of the topographer. In order to give practice in expression, a portion of a campus was chosen which combines steep and gentle slopes. A sketch of the region that was mapped is shown in Fig. 4. The first thing to be decided was the scale and the contour interval. The dimensions of the 
map were 6 by 5 inches and that of the area to be mapped, about 200 by 100 feet. The scale was fixed at 30 feet, or twelve paces to the inch, this being a convenient unit for the size of the map. The difference in height between the highest and lowest points is about 20 feet; the contour interval was taken at five feet, or, for convenience, the distance from the eye to the ground.

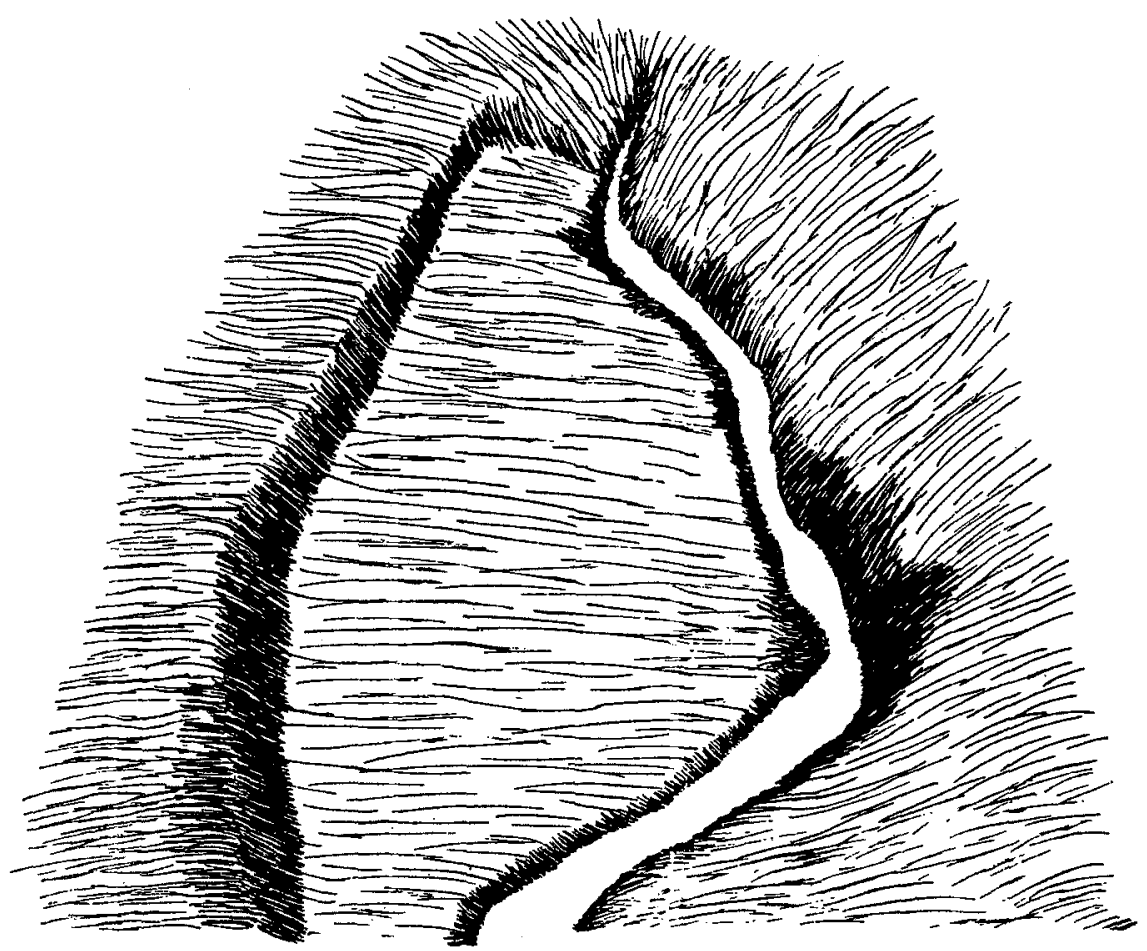

FIG. 4

A sketch of the area mapped.

The plane table was not used. The idea was to employ as simple apparatus as possible, both because such apparatus is easy to obtain and because the principle is much more easily grasped when simple apparatus is used. A drawing pad was placed on the ground and by means of a hand compass was oriented (Fig. 3), the top of the map being placed to the north. The base line A, B, Fig. 2, was drawn along a straight level path and was made thirty feet in length. This length was chosen because the level part of the path was about that long; it was represented on the map 
by a line one inch long. Its direction was obtained by placing a ruler on the map and sighting to get the ruler in the direction of the path.

Having determined the base line and its representation on the map, the location of trees and other objects was an imitation of the topographer's traverse methods. The reading of angles, of course, was not attempted, and the intersection method was but little followed. To locate a tree, for example, one would pace from one end of the base line and determine its distance. Its direction of, say, northeast Io degrees, could be found by the compass and the line plotted on the map, but with a small area there

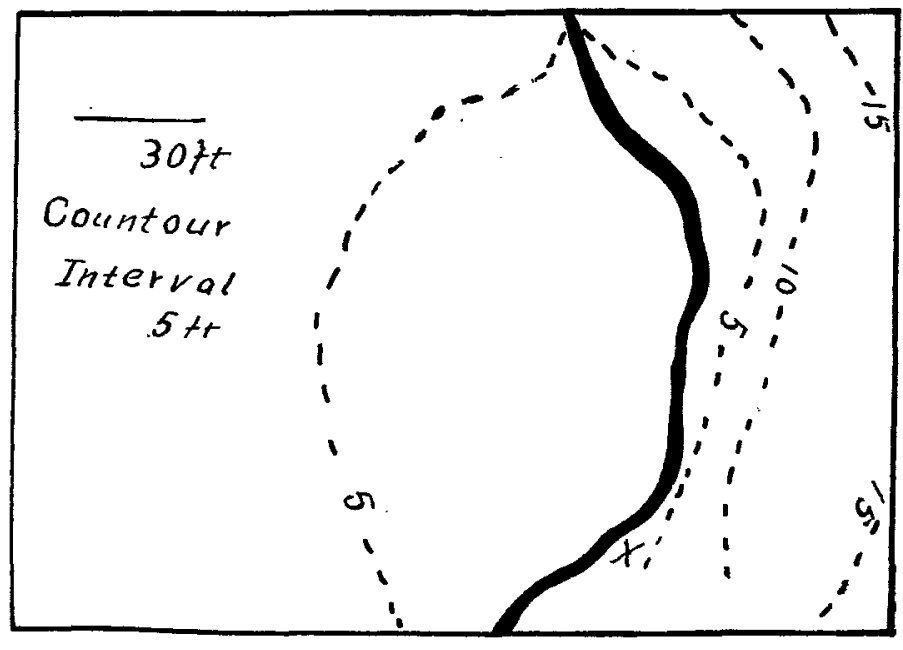

Fig. 5

A contour map of area sketched in Fig. 4.

was little error in sighting to the tree along the ruler on the map and assuming that the line along the ruler would coincide with a line determined by the compass, Fig. 3. For large objects it was found sufficiently accurate to take a protracter to one end of the base line, repeat the process at the other end, and then find the position of the object on the map by the intersection method. Fig. 2 shows the map on which intersections were made.

Having located a few points the contouring can be taken up. For simplicity the lowest part of the region is taken as zero; it is generally found in the water channel. The lowest spot shown on the map is marked $X, F i g s .2$ and 5 and from this point altitudes were measured. Standing at point $\mathrm{X}$, obviously all points on a level with the eye would belong in 
the first five foot contour line. The problem is to find the points in such a plane. Unless one has tried the experiment, it is difficult to realize how easy it is to under or over estimate altitudes. There are many ways in which this can be done with accuracy. For instance, if one should take a carpenter's level and holding it horizontal, look along it, all objects seen in the plane of the level would be in the same plane as the eye. This is the principle of the Locke level which is used for this purpose and which is more convenient.

However following the plan of using simple instruments, we employed a crude but simple method. If one looks across the level top of water in a glass tumbler, obviously it serves the purpose of the Locke level. The level may be ascertained since the water's edges on both sides of the glass are in the same plane. The chemist's " $U$ " tubes serve the purpose well. The standing figure in Fig. 3, illustrates the method.

It is well for one person to act as "marker" by placing paper, stakes, etc., to mark the levels. Where the slope is small these may be some distance apart but where the slope is steep or the surface broken, the markers should be closer. If desirable, some of the markers can be located on the map, e. g., m-m Fig. 2, to guide in sketching. When a good idea of the location of the first contour is gained, the contour should be sketched upon the map. After the first contour is drawn, the process can be repeated by taking a point ten feet above the zero point, or five feet above the first contour, and repeating the process. The same procedure can, of course, be repeated for any contour.

In practice the two operations of locating objects and getting data for altitudes can be combined, especially after the first contour is drawn. They have been described separately for the sake of clearness. The work should be watched especially where the contours cross a valley for this seems to be a stumbling block in reading and drawing maps. The widening of the space between contours in gentle slopes and its narrowing on steep slopes were espcially valuable in giving an almost unconscious facility in understanding a map. The completed map looked something as in Figure 5 .

After the field map was completed and corrected, a day was spent in map sketching. Some of the problems were: draw a deep valley with a steep slope; with gradual slope; a valley with a slope of ro feet per mile. Draw a hill 50 feet high, contour interval ro feet; draw the same with a valley on the $N$. W. side, 20 feet deep at the mouth; a hill with a slope of $\mathrm{I}$ feet to the mile on the east side and 20 feet on the west side. Place a smaller hill 20 feet high on the east side. 